\title{
E-learning in a virtual science camp for urban youth
}

\author{
Lynne Holden $^{\mathrm{a}, \mathrm{b}, *}$, Andrew Morrison ${ }^{\mathrm{b}}$, Wallace Berger ${ }^{\mathrm{c}}$ and Elliot Siegel ${ }^{\mathrm{d}}$ \\ ${ }^{a}$ Clinical Emergency Medicine, Albert Einstein College of Medicine, Bronx, NY, USA \\ ${ }^{\mathrm{b}}$ Mentoring in Medicine, Bronx, NY, USA \\ ${ }^{\mathrm{c}}$ LightShift Associates, LLC, Viera, FL, USA \\ ${ }^{\mathrm{d}}$ Elliot Siegel Consulting, Bluffton, SC, USA
}

\begin{abstract}
The Virtual Science Camp (VSC) is a unique demonstration of synchronous e-learning developed by Mentoring in Medicine (MIM). This paper reports on a pilot offering during the summer of 2012 that taught advanced biological concepts, healthy living and health care career opportunities to medically underserved urban youth. Livestream's interactive video technology was used to engage a diverse audience of mostly high school students at remote sites in a new two week instructional program that provided custom course content free of charge over the internet. We describe the technical and program preparations undertaken, their implementation, the IT environment, a multi-faceted evaluation plan, the results of the experiment, and lessons learned.

Keywords: Synchronous e-learning, youth development, health careers
\end{abstract}

\section{Introduction}

Mentoring in Medicine, Inc. (MIM) is a 501(c)(3) non-profit organization founded in 2006 by three emergency medicine physicians. MIM seeks to develop non-traditional educational experiences that (1) foster underrepresented minority student interest in the health professions; (2) contribute to the societal goal of increasing workforce diversity; and (3) thereby, improve health services and patient outcomes in underserved minority communities. The core goal is to turn dreamers into health professionals through academic enrichment, leadership development, civic engagement, and mentoring. MIM is based in New York City and has local activities in the metropolitan DC area, New Orleans, Philadelphia, Detroit and Atlanta. MIM receives financial and in-kind support from individual volunteer health professionals and local community organizations. Supporters include the outreach programs of the US National Library of Medicine (www.nlm.nih.gov), the Friends of the National Library of Medicine (www.fnlm.org), the Department of Emergency Medicine of the Albert Einstein College of Medicine (www.einstein.yu.edu), Montefiore Medical Center (www.montefiore.org), and the Robert Wood Johnson Foundation (www.rwjf.org).

In 2009, the Mentoring in Medicine (MIM) organization (www.medicalmentor.org) instituted a pilot After School Program (ASP) for high school students in medically underserved communities, designed to increase health literacy and to foster interest in the nearly 120 health careers currently available

\footnotetext{
${ }^{*}$ Corresponding author: Lynne Holden, MD, Montefiore Medical Center, Department of Emergency Medicine, Rosenthal SE, Room 201, 111 East 210th Street, Bronx, NY 10467, USA. E-mail: Holden@ medicalmentor.org.
} 
(www.science.education.nih.gov/lifeworks, www.explorehealthcareers.org). These range from ancillary professions such as laboratory and X-ray technical assistants requiring a certificate or diploma, to those requiring a post-graduate professional degree, such as medicine and dentistry. The data from the American Association of Medical Colleges (AAMC) show that in 15 years, the diversity of the applicant pool for health professional schools has not changed significantly. The percentage of medical school applicants who are African-Americans, Hispanics, and Native Americans are disproportionately below their make-up of the entire population and, combined, are less than fifteen percent [4].

The MIM ASP in the New York City high school system has been offered 45 times in up to 7 high schools in Harlem and the Bronx. Approximately 800 African-American and Hispanic students have volunteered and completed one or more semesters. During the last two years, the course curriculum and measurement instruments have been refined and systematic evaluations performed. The most recent results for the Spring 2013 semester are consistent with those achieved earlier [2]. In summary, school principals, teachers, students, and parents are enthusiastic about the program and its potential impact on student academic success and future career choices in the health care professions with the desired outcome of increasing diversity and improving health services in underrepresented minority communities. Students demonstrated an increase in knowledge of the subject matter presented, with each semester covering three of twelve organ systems, along with the frequently occurring health conditions and associated diseases [6]. A companion course, the In-School Program (ISP), was offered in 5 New York City high schools as an in-school for credit elective. Approximately 121 students completed one or more of the 10 semester-long classes offered during the 2012-2013 school year [3].

In a new effort to broaden access to its offerings beyond the time constraints of the academic school year and daily class instruction, MIM launched a pilot project in the summer of 2012 utilizing distance learning tools to support live and recorded course presentations. The Virtual Science Course (VSC) is offered free of charge, and requires only commonly available devices such as cell phones, tablets, desktop or laptop computers with broadband Internet connection.

Contextually, the impact of the Internet on education is growing significantly. College and graduate students who took at least one online course in 2011 have increased to an estimated 6.7 million students, up from 1.6 million at the start of the decade [1]. Moreover, these students can be expected to engage in lifelong learning experiences throughout their careers in the workplace and from home, through network technologies that will continue to advance in interactive capabilities as bandwidth accessibility improves and costs decline. E-learning that features a high level of interactivity is referred to as synchronous, and is commonly supported in real time by media such as video conferencing and chat. It has the potential to foster communities of learners who are aware of themselves as members of a group, rather than isolated individuals communicating with a computer [5]. Another form of e-learning is asynchronous and enables participants' learning when they cannot be online at the same time and is commonly facilitated by media such as email and document downloads. Numerous educational studies have sought to compare the relative efficacy of each under different learning conditions and requirements [7].

Most e-learning for high school students is asynchronous, such as with the Kahn Academy (www. kahnacademy.org) and WatchKnowLearn (www.watchknowlearn.org). Use of synchronous e-learning strategies among minority urban youth is particularly rare. Mentoring in Medicine elected to utilize the closing digital divide in urban areas among an increasing number of youth that can access the Internet in order to employee it as a tool for educational enrichment in the sciences. Consequently, the Virtual Science Camp (VSC) was launched in the summer of 2012 as a pilot program in synchronous e-learning for teaching advanced biology, healthy living and health career opportunities. 


\subsection{The Virtual Science Camp (VSC)}

The VSC objectives are to offer synchronous e-learning academic enrichment to underrepresented minority high school students throughout the United States and internationally in order to (1) explore a variety of careers in the health professions; (2) increase their information seeking behaviors about health; (3) improve their health literacy and understanding of health disparity issues; (4) improve their test-taking and study skills; and (5) understand advanced biological concepts and diseases of the cardiovascular system. The initial course presentation was offered over a two week period in July 2012. The MIM organizers put in place prototype measurement tools to assess the student experience, along with measures of the technical performance and utilization of the VSC information technology infrastructure.

\section{Methodology}

Multiple methodologies were used to develop, implement, and evaluate the Virtual Science Camp (VSC) program. (See Fig. 1.) These included the use of Livestream, a commercially available information technology environment; custom course content and curricula especially developed for this pilot; weblog data analysis; student surveys; and student projects. A cadre of mostly volunteer educational and technical staff was utilized. Formal grades were assigned to students and certificates of completion were awarded at the end of the VSC. Exemption from Institutional Review Board (IRB) protection of human subjects review was granted by the Albert Einstein College of Medicine in New York.

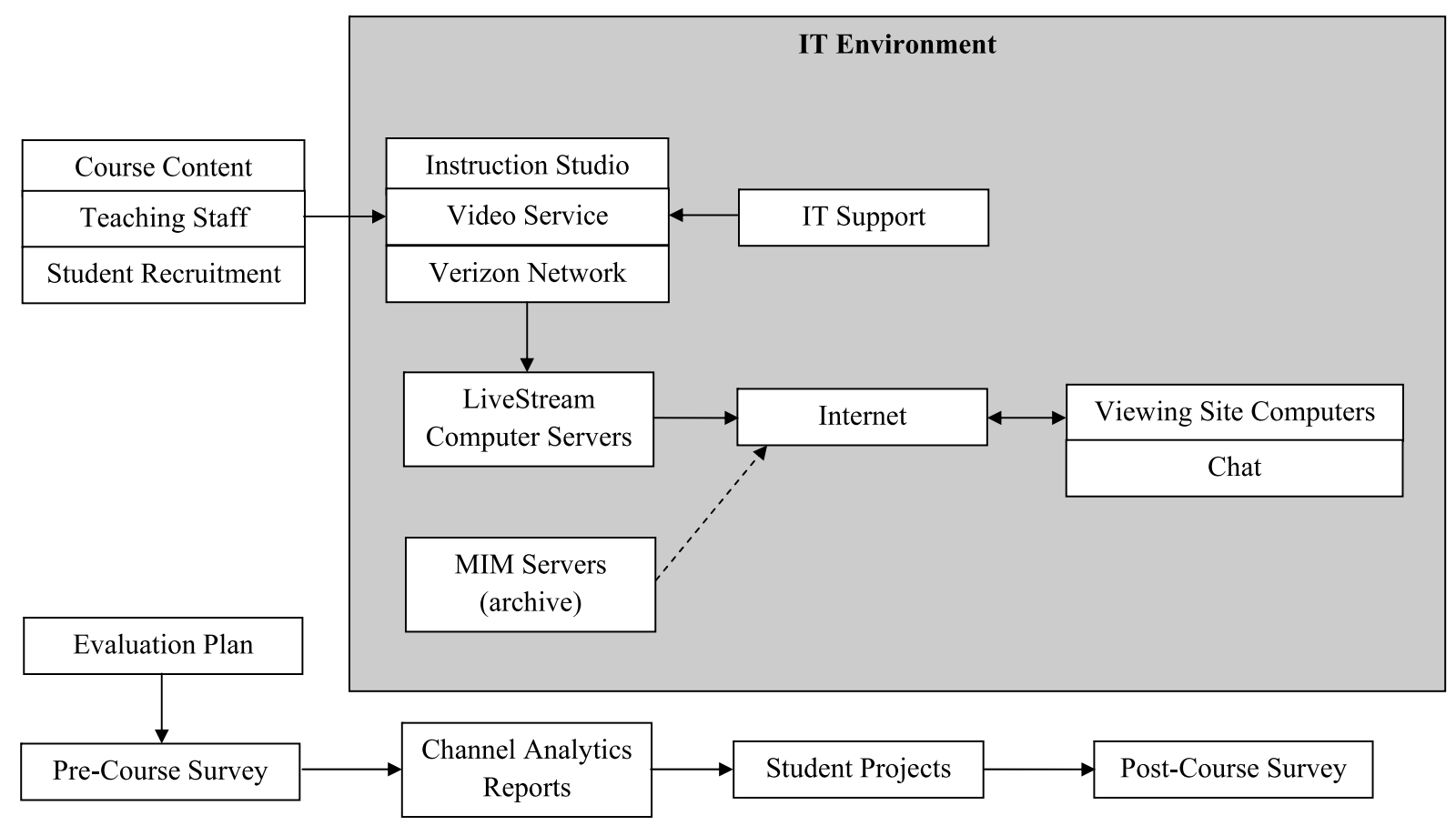

Fig. 1. Technical and program elements used to develop, implement and evaluate the VSC. 


\subsection{Course development}

Content: Ten classes on the cardiovascular system, including anatomy, physiology, and associated diseases comprised the custom VSC curriculum. Visiting health professional instructors spoke about their own careers and how it pertained to the system being covered. Students were also given instruction on composing a scientific presentation; understanding medical terminology; strategies for becoming competitive applicants to health professional school; the cardiovascular system (structure, function and diseases); dissection of a pig's heart; and how to develop a final student presentation.

Staff: A variety of staffing and skill sets were required to develop and offer the VSC. These included a Curriculum Writer; Videographer (2); Audio Technician; MCs (2); Physician Instructor (4); other Health Professional Instructor (4); Video Editor; Technical Assistant; Computer Assistant; Evaluator; College/Graduate Students (5) and a Research Assistant.

Student recruitment: Students were recruited from an e-blast to a limited portion, approximately 500 students, from the MIM internal list. The list consisted of names of students who have participated in national MIM events and who have signed up on the MIM website. Registration was anonymous and booked online at http://mimcamp.eventbrite.com.

\subsection{The IT environment}

The VSC employed a video streaming service offered by LiveStream (www.livestream.com), a multitiered premium service free of advertising. The 'LiveStream Producer' application was procured for the VSC pilot experiment. Lectures were broadcast live in real-time. The platform allows customers to broadcast content over the Internet using a video camera and computer from a central classroom 'studio.' One way video streaming to many was webcast with chat and e-mail used for two way communication. The content was accessible from multiple websites, enabled with embedded code provided by MIM especially for this purpose. Content was also archived on the MIM website for later asynchronous viewing. User viewing activity both live and archived was captured, logged and reported by LiveStream in the form of Channel Analytics Reports.

Video Service: The video equipment at the broadcast site consisted of a SONY DVX-2100 camera and a Black Magic H 264 Pro Recorder encoding device transmitting programs in real time to streaming servers.

IT Support: Programs were 1-3 h to set up and monitor the broadcast. Three college students provided in-class support and one student handled questions that appeared in the chat room and via email.

Streaming Servers: The original encoded content was retransmitted by servers provided by LiveStream and capable of supporting 10,000 simultaneous viewers.

Network: Verizon 4G LTE Wi-Fi (upload speed of $5 \mathrm{MB} / \mathrm{s}$ ) was used to transmit encoded content to the streaming servers.

Viewing Site Computers: Mac or PC supported computers at the student sites required a minimum of $500 \mathrm{MB}$ of RAM and $450 \mathrm{MHz}$ processors. The required Internet download speed was set at $700 \mathrm{~Kb} / \mathrm{s}$. Java Script and the 'cookie' settings were enabled.

Instruction: Course content delivered live from Thurgood Marshall Academy in New York City. Some 15 students (10 high school and 5 college or graduate student volunteers) comprised a live audience for their instructors who appeared in person, called-in, or joined via Skype. Pre-recorded video, PowerPoint slides, and student comments communicated to instructors and/or each other via text 'chat' were aired on a projection screen that was viewable at the remote sites. 
Duration: The VSC consisted of 10 sessions broadcast from July 9 to July 20 from 2pm-5pm EST. User data was collected from July 1 through August 10, which was past the official close of the course since students missing sessions due to vacations or other commitments could view archived sessions on the MIM website. A typical day consisted of an initial current events discussion related to science and medicine in the news; a lecture; guest speaker; reading and note taking; an interactive knowledge game and quiz; a review of the session and journaling. Specifically, journaling consisted of the blog that each student created every day about what they learned which was housed on their website.

\subsection{Channel analytics reports}

Livestream automatically compiled usage data about: (1) Geolocation of students based on viewers' computer IP addresses; (2) Audience activity including number and duration in minutes of Daily Viewers, Daily Unique Viewers, Daily Streams, Daily Peak Viewers; and (3) Most frequently viewed content.

\subsection{Student pre- and post-course surveys}

All students taking the course were requested to complete a pre-course survey consisting of 20 structured and open-ended questions covering demographics, information seeking behaviors; and career interests. A 31 question post-course survey repeated several of these questions permitting pre- and postcourse comparisons and, in addition, posed questions on frequency of class participation, subject matter knowledge gained, suggestions for course improvement, and career intentions.

\subsection{Student course projects}

All students were required as a condition of the VSC fulfillment to complete an individual class project for presentation in a virtual science and health fair. They were given a wide choice of healthy living projects that could be undertaken, including a two-page paper, a Power Point presentation, cartoons, video games, or a one-page spoken word/rap with video.

\section{Results}

\subsection{Channel Analytics Reports}

Channel Analytics Reports provided by Livestream gave an overview of student/viewer activity. These totaled approximately 160,000 viewer minutes; 5,700 video streams; 21 average viewer minutes; and 1,200 unique visitors. These data are limited in that a single IP address may service multiple viewers at a single computer station. Of greater concern is that a disproportionately large and unknown number of 'accidental' viewers may simply have found the VSC website without intending to enroll. It is suspected that an observed drop in views after the first two classes - from a high of 230 in Session 2 to a more consistent 90 unique sign-ons per subsequent sessions - was due to this phenomenon, which led also to an unreliable average viewer time metric. The latter was also affected by students who viewed a class live and later reviewed the same content again. It is believed that a more accurate measure of average viewing time per session is in an estimated range of 100-166 average viewing minutes per unique visitor per $3 \mathrm{~h}$ live sessions. 
Geolocation of participants was $99 \%$ in the United States with a small scattering of viewers in Canada, the United Kingdom, Continental Europe, and the Caribbean.

IT Infrastructure Reliability was high. On the broadcast side, there were two instances of a drop in digital strength on the high school's in-house wireless system. This was quickly remedied by a switch to the Verizon LTE 4G mobile broadband connection that had been installed as a backup measure, and was subsequently used for all further broadcasts without interruption. Two instances of sound loss were attributed to dead batteries in portable microphones. All downloaded sites were provided with a troubleshooting and help guide that identifying potentially avoidable problems and the means to resolve them. For example, sites that experienced poor video quality were advised to restart their computers and only login to the Livestream broadcast or if audio was lacking to make sure that the speakers were turned up.

\subsection{Student Pre- and Post-Course Survey Data}

Student Pre- and Post-Course Survey Data reveal the following findings:

Pre-course survey responses were received from 160 students. As there was no formal registration process, the actual rate of compliance is unknown. At the conclusion of the VSC, 72 students completed the companion post-course survey. A total of 55 students completed both surveys, thus offering some opportunity to compare changes to answers in a small subset of questions that appeared on both surveys. These 55 students were the participants that, most likely, were exposed to all of the VSC content.

It is interesting to note that the number of survey participants is roughly comparable to the number of unique visitors recorded by Livestream. That is, an average of 90 unique viewers accessed a VSC session during the second week of the course, down from the initial high mark of 230 viewers of session 2 . This suggests a possible survey completion rate that may be as high as $69 \%$ on the pre-course survey (230 unique viewers and 160 surveys) and $80 \%$ on the post-course survey (approximately 90 unique viewers and 72 surveys), but these can only be best-guess estimates in the absence of actual student registration data.

Course attendance and viewing methods: Students self-reported as the modal response that they were present for class "every day". The most frequently identified method of viewing the course was from a "laptop" (58\%), another 38\% used a "personal desk computer at home".

Student demographics: A preponderance of females (82\%) participated in the course. With respect to attained educational level, the majority of students - in excess of $60 \%$, were in high school. The range was from the youngest respondent completing the 8th grade and the oldest being college graduates. Some $20 \%$ of the VSC students had college experience. Thus it can reasonably be assumed that at least some had previously participated in an online learning program. The vast majority had not, however, nor had they had such experience using an IT learning environment for the purpose of studying the cardiovascular system and associated health careers. This was a unique opportunity for a cohort of underrepresented minority high school students to apply the online learning experience to the health care domain.

Surveys revealed the following about the impact of the VSC on student knowledge, attitude, and behavior with respect to the VSC objectives of:

Information seeking behavior: Of the 55 students completing both the pre- and post-course surveys, we found statistically significant differences $(p \leqslant 0.01)$ with respect to changes in self-reported information seeking behavior. That is, the course favorably impacted students' "reading about heath care subjects of interest" (27 additional minutes per day); "talking to friends about careers in the health field" (18 additional minutes); and "talking to family members about these careers" (also 18 additional minutes). 
Exploring health career: Further evidence of VSC impact may be gleaned from those students completing the post-course survey and who reported on 5-point Likert-type attitude scales that they agreed or strongly agreed $(44 \%)$ that the course "inspired me to pursue a health career" (mean $=4.3$ ); "helped me to learn about various health careers and the educational path" (mean $=4.3$ ). The VSC seems also to have encouraged students to pursue a specific health career, or reinforced an existing favorable predisposition to do so. Although students identified a variety of health careers they were interested in pursuing, surprisingly, careers requiring an advanced degree were those most frequently mentioned: medical doctors of all types (50\%); with some $20 \%$ of those students indicating they wanted a career in pediatrics.

Test-taking and study skills: Thirty-eight percent of the participants strongly agreed that the Program "taught me new study skills" (mean = 4.1).

Understand biological concept: Subject matter content was also well mastered with students indicating that the course "helped me to learn about the structure and function of the cardiovascular system" $($ mean $=4.6)$ and "helped me to learn about diseases of the cardiovascular system" (mean =4.6). Some $60 \%$ of the course content was, on average, new to the students so these high levels or agreement are suggestive of significant knowledge acquisition. Moreover, they expected to remember $80 \%$ of it after the course.

Health literacy: Improvement in students' health literacy and understanding of health disparities issues may be inferred from $42 \%$ of the students strongly agreeing with the statement that the course "inspired me to live a healthy life" (mean $=4.2$ ).

Satisfaction: Finally, $42 \%$ of the participants strongly agreed that they would recommend the VSC to a friend.

\subsection{Student projects}

A total of 55 certificates were issued to students fulfilling all requirements for course completion, including the design of their own website, maintenance of a daily blog, completion of the post-course survey, and creation of a healthy living project. The submitted projects demonstrated substantial understanding of course content relating to a particular cardiovascular health condition or career choice covered in the course, along with entertaining elements that appeal to the sensibilities of fellow high school students. Examples of these student projects have been posted to the MIM website www.medicalmentor.org, and they may be viewed by clicking on 'MIM Television'.

\section{Discussion}

From a technological standpoint, video streaming of the kind used in this pilot experiment has evolved over the past decade. Beginning with educational research programs of this kind initially pioneered by the National Library of Medicine's experiment to simulcast videoconferences via webcast with a chat feature for audience interaction [9] and subsequent research studies $[8,10]$ to widely available commercial services such as provided by Livestream. Other Internet-based products like Adobe Connect popular in the academic and business communities support multi-user conferencing, including the sharing of slides with a built-in chat feature. The rapid proliferation of Cloud Computing offers the opportunity to carry on a live multipoint videoconference over the Internet, and simultaneously webcasting to a larger audience. 
In the educational arena, the pedagogical benefits of two-way interaction are well understood and include an ability to receive immediate feedback, while promoting student engagement with the teacher, content, and learning community [11,12] Technically, the inclusion of an instant chat capability can be particularly helpful in circumstances where it may not be practical to support two-way videoconferencing given the required bandwidth on both ends. Moreover, chat is finding expression in myriad ways outside the educational setting. The phenomenon of instant message via mobile phone is becoming ubiquitous in life, as is the widespread adoption of social networking systems with messaging components. In the VSC, we have anecdotal evidence that he use of online chat allowed a robust student-faculty and student-student interaction. This chat was monitored by the college and graduate student volunteers. However, due to the rapidity and overlapping nature of the chat messages submitted, there was no reliable mechanism in place to measure the traffic and analyze its contents. The Livestream system had no functionality to do so either. This will need to be remedied in future implementations of the VSC.

Thus, the VSC implementation may not be particularly unique technologically or pedagogically. But its use with this special population for these socially desirable purposes that include encouraging underrepresented minority, urban, high school youth to pursue careers in the health care professions is.

There are several limitations regarding the implementation of the VSC in the summer of 2012 and the evaluation protocols employed that will need to be remedied in the next iteration of the VSC in 2013. Perhaps the issue of most concern is the failure to register student participants so an accurate measure of student enrollment could be obtained, and the related absence of identity authentications placed on persons accessing one or more course sessions out of curiosity without intending to actually take the entire course. Similarly, the pre- and post-course surveys did not employ an assigned unique personal identifier, so completed surveys could not always easily be linked to the same persons. Next, there were too few identical questions used in both pre- and post-course surveys that limited the evaluation of changes in student knowledge, attitude, and behavior. Lastly, as previously noted, a reliable means for recording and measuring chat traffic is needed.

It was also observed that the successful application of information technology in a distance learning environment may be a necessary but not a sufficient condition to achieve the desired objectives of the VSC. While the formal lectures given by expert health professionals went exceedingly well, these were balanced in the flow of a typical day by other interpolated learning activities that retained student interest and attentiveness and enhanced their motivation to learn. For example, the writing and discussion each day of student journal blogs provided an excellent opportunity to summarize the events of the previous day's session, and introduce the learning objectives of the current day. The student projects were, in particular, a very positive means to create and reinforce the benefits of experiential learning. Real time display and peer acknowledgement of students' projects provided additional incentives to excel. Live health professionals demonstrated dissections and life saving techniques and answered questions via chat. Current events involving celebrities and known health challenges were utilized to enhance student interest.

\section{Lessons learned}

A formal registration package should be developed that details course expectations, course agenda, project rubric and criteria for earning a certificate and community service credit. The broadcast should be password protected with access gained through completion of registration materials. 
Table 1

Mapping VSC objectives against measurement methods

\begin{tabular}{ll}
\hline Objective & \multicolumn{1}{c}{ Methods } \\
\hline Develop interest in health care careers & Pre-Post questions about career interests \\
Use technology for healthy living info & Post questions on technology effectiveness \\
Learn health disparity issues & Pre-Post Health Disparity Test \\
Seeking information about heath & Pre-Post information seeking behavior \\
Understand the Cardiovascular system & Pre-Post Cardiovascular Knowledge Test \\
Improve test-taking and study skills & Pre-Post Study/Test Skills Test \\
Favorable impression of the Course & Post questions on Course organization and value \\
\hline
\end{tabular}

A number of parents registered for the course. Materials should be developed for parents to learn about the path to college and health professional school including resources for financial aid and internship opportunities.

A sixth and seventh objective for the VSC have been identified and should be explicitly incorporated in new courses and their evaluation going forward such as the use of technology as an effective means for imparting information about healthy living and that students should be left with a favorable impression of the value of the VSC.

An evaluation plan that maps the seven VSC objectives against pre- and post-course surveys and tests of registered students is shown in Table 1.

\section{Conclusion}

The Summer 2012 VSC provided further encouraging evidence of the feasibility of using interactive information technology to support distance learning in a dispersed educational environment. The uniqueness of the present effort centered on its means to reach and engage underserved minority students in a shared group effort. The goal was to help students learn complex scientific content and terminology, apply it to their understanding of disease processes, and relate it to careers in the health professions that they may reasonably aspire to pursue in the future. The VSC objectives were satisfied in that (1) students explored a variety of careers in the health professions; (2) increased their information seeking behaviors about health; (3) improved their health literacy and understanding of health disparity issues; (4) improved their test-taking and study skills; and (5) understood advanced biological concepts and diseases affecting the cardiovascular system which was the subject matter of this initial VSC offering.

Additional research is needed to refine the VSC's recruitment and identification of students, sharpen the evaluation tools that may be used to strengthen the ability to produce robust findings that clearly demonstrate the specific impact sought. In particular, these should relate to changes in the cascading chain of improved student knowledge, meaningful shifts in attitude, and positive motivational changes in student behavior leading to the pursuit of a career in one of the many health care professions. The VSC was repeated in Summer 2013 with a larger audience, and specific changes were made that address and remedy most of the limitations identified in this initial pilot implementation.

\section{Acknowledgements}

We would like to express appreciation to Craig Locatis, $\mathrm{PhD}$ and Michael Ackerman, $\mathrm{PhD}$ at the National Library of Medicine (NLM) reviewed an earlier draft and made numerous suggestions that 
greatly improved the paper. Special thanks to Patricia Carson, project officer for MIM on behalf of NLM. MIM was supported by NLM Contract Number HHSN276201100017C in 2012 and the Robert Wood Johnson Foundation 2009 Community Health Leaders Award.

\section{References}

[1] I. Allen and J. Seaman, Changing Course: Ten Years of Tracking Online Education in the United States, Report, Babson Survey Research Group, 2013, p. 17, available at: http://sloanconsortium.org/publications/survey/changing_course_2012.

[2] W. Berger, Evaluation Report for Spring 2013 After School Program, Mentoring in Medicine Internal Report, July 5, 2013. (Available from the primary author.)

[3] W. Berger, Evaluation Report for Spring 2013 In-Class Program, Mentoring in Medicine Internal Report, July 9, 2013. (Available from the primary author.)

[4] L. Castillo-Page (ed.), Diversity in Medical Education: Facts \& Figures 2012, American Association of Medical Colleges, Washington, DC, 2012.

[5] C. Haythornthwaite and M. Kazmer, Bringing the Internet home: adult distance learners and their Internet, home and work worlds, in: The Internet in Everyday Life, B. Wellman and C. Haythornthwaite, eds, Blackwell Publishing, Malden, MA, 2002, pp. 431-463.

[6] L. Holden, A pilot after school program in advanced human biology, health disparities and biomedical careers, in: Ninth Annual AAMC Physician Workforce Research Conference, Alexandria, VA, May 2-3, 2013.

[7] S. Hrastinski, Asynchronous and synchronous e-learning, Educause Quarterly 4 (2008), 51-55.

[8] C. Locatis, E. Berner, G. Hammack, S. Smith, R. Maisiak and M. Ackerman, Communication and proximity effects on outcomes attributable to sense of presence in distance bioinformatics education, BMC Medical Education 11(10) (2011), PMID: 21401942, PMCID: 3068129, DOI: 10.1186/1472-6920-11-10.

[9] C. Locatis, P. Fontelo, C. Sneiderman, M.S. Ackerman, S. Uijtdehaage, C. Candler, S. Stensaas and S. Dennis, Webcasting videoconferences over IP: a synchronous communication experiment, J. Am. Med. Inform. Assoc. 10(2) (2003), 150-153.

[10] C. Locatis, A. Vega, M. Bhagwat, W. Liu and J. Conde, A virtual computer lab for distance biomedical technology education, BMC Medical Education 8(12) (2008), PMID: 18366629, PMCID: 2292716, DOI: 1186/1472-6920-8-12.

[11] F. Martin, M. Parker and D. Deale, Examining interactivity in synchronous virtual classrooms, International Review of Research in Open and Distance Learning 13(3) (2012), 227-261.

[12] J. McBrien, P. Jones and R. Cheng, Virtual spaces: employing a synchronous online classroom to facilitate student engagement in online learning, International Review of Research in Open and Distance Learning 10(3) (2009), 1-17. 